\title{
LUT
}

University

\section{Removal of calcium and magnesium from lithium brine concentrate via continuous counter-current solvent extraction}

\author{
Virolainen Sami, Fallah Fini Mojtaba, Miettinen Ville, Laitinen Antero, Haapalainen \\ Mika, Sainio Tuomo
}

This is a Final draft version of a publication

published by Elsevier

in Hydrometallurgy

DOI: $10.1016 /$ j.hydromet.2016.02.010

Copyright of the original publication: (C) 2016 Elsevier B.V.

Please cite the publication as follows:

Virolainen, S., Fallah Fini, M., Miettinen, V., Laitinen, A., Haapalainen, M., Sainio, T., 2016. Removal of calcium and magnesium from lithium brine concentrate via continuous countercurrent solvent extraction. Hydrometallurgy 162, 9-15. doi:10.1016/j.hydromet.2016.02.010

This is a parallel published version of an original publication. This version can differ from the original published article. 


\title{
Removal of calcium and magnesium from lithium brine concentrate via continuous counter-current solvent extraction
}

\author{
Sami Virolainen ${ }^{\mathrm{a},{ }^{*}, \text { Mojtaba Fallah Fini }}{ }^{\mathrm{a}}$, Ville Miettinen ${ }^{\mathrm{b}}$, Antero Laitinen ${ }^{\mathrm{c}}$, Mika \\ Haapalainen $^{\mathrm{d}}$, Tuomo Sainio ${ }^{\mathrm{a}}$ \\ ${ }^{a}$ Lappeenranta University of Technology, Laboratory of Separation Technology, P.O. Box 20, FI-53851 \\ Lappeenranta, Finland \\ ${ }^{b}$ Technical Research Centre of Finland, Skinnarilankatu 34, FI-53850, Lappeenranta, Finland \\ ${ }^{c}$ Technical Research Centre of Finland, P.O.Box 1000, FI-02044, Espoo, Finland \\ ${ }^{d}$ Outotec (Finland) Oy, P.O.Box 69, FI-28101 Pori, Finland \\ *Corresponding author.Tel.: +358 40 7093444, E-mail address: Sami.Virolainen@lut.fi
}




\section{Abstract}

In this research project, a process for purifying $\mathrm{Li}$ brine concentrate with a typical composition of Li $30 \mathrm{~g} / \mathrm{L}, \mathrm{Ca} 1.36 \mathrm{~g} / \mathrm{L}, \mathrm{Mg} 0.049 \mathrm{~g} / \mathrm{L}$ via solvent extraction was studied. The goal was to remove $\mathrm{Ca}$ to below $20 \mathrm{mg} / \mathrm{L}$ and $\mathrm{Mg}$ to the ppm level while keeping the co-extraction of Li below $10 \%$. Laboratory-scale batch experiments showed that conventional cation-exchange reagents D2EHPA and Versatic 10 could be used for the task in $\mathrm{pH}$ ranges of 3.5-4.0 and 6.5-8.0, respectively. Of these reagents, Versatic 10 had better selectivity for the target metals and better phase disengagement properties, while D2EHPA had a higher capacity. However, with either of these reagents, the organic phase cannot be loaded to a very high extent, because $\mathrm{Ca}$, which has the highest affinity, then replaces $\mathrm{Mg}$.

The effect of the operating parameters ( $\mathrm{pH}$, temperature, phase ratio, and residence time) were studied in a bench-scale two-stage continuous counter-current setup with both reagents. The overall performance was good, yielding ppm impurity levels in terms of Ca and $\mathrm{Mg}$ and, typically, 3-5\% Li co-extraction. While the Mg extraction could be increased by increasing the $\mathrm{pH}$ in the mixers and decreasing the $\mathrm{A} / \mathrm{O}$ phase ratio, the Li co-extraction would also be increased. A compromise must be made between purity and Li yield. Decreasing the temperature or residence time did not have a significant effect on performance. It was demonstrated that a high throughput can be achieved because a mixer residence time of 2 min or even less can be used.

\section{Keywords}

Lithium; Brine; Calcium; Magnesium; Continuous counter-current solvent extraction 
1. Introduction

The demand for lithium is expected to increase almost 4-fold from 2011 to 2025, mainly due to its use in batteries, especially those used in electric vehicles (Cabeza et al., 2015). According to a Mineral Commodity Summaries report (United States Geological Survey, 2015) $31 \%$ of $\mathrm{Li}$ is used in batteries, with other uses including, for example, glass and ceramics, greases, rubbers, and the pharmaceutical industry (Meshram et al., 2014).

Brines are the most important Li source, and most of the worldwide reserves are located in brines (21.6 Mt). Pegmatite ores contain 3.9 Mt of Li and other types of primary raw materials 5.4 Mt. Also, the recovery of Li from the brines is easier and more economical than recovery from other sources (Kesler et al., 2012; Meshram et al., 2014). The recycling rate for Li was reported to be only 3\% in 2011 (Talens Peiró et al., 2013).

An et al. (2012) have listed the most important Li-containing brines and their compositions. The brine deposits are located in South America, China, the USA, Israel, and India. The main component is $\mathrm{NaCl}$ ( $\mathrm{Na}$ content $4.7-11$ wt.-\%), Li content is $0.001-0.16$ wt.-\%, and the minor elements and compounds of varying concentrations include $\mathrm{K}$ (0.2-2.4 wt.-\%), B (0.003-0.071 wt.-\%), $\mathrm{Mg}\left(0.003-3.09\right.$ wt.-\%), Ca (0.002-3.9 wt.-\%), and $\mathrm{SO}_{4}{ }^{2-}(0.061-$ 50 wt.-\%). The most significant of these impurities is $\mathrm{Mg}$ because $\mathrm{Mg}$ and Li are not easily separated due to their similar chemical natures. Thus, only those brines with low $\mathrm{Mg} / \mathrm{Li}$ ratios are used industrially for Li production (Liu et al., 2014).

According to Garrett (2004), the basic process for recovering Li from brines is as follows: 1) Solar evaporation, in which a large portion of the other salts (e.g. $\mathrm{KCl}, \mathrm{NaCl}$ ) are removed; 2) precipitation of impurities (B, sulfate, and $\mathrm{Mg}$ ); and 3) precipitation of Li with 
soda ash. The drawbacks of the described method are that the recovery of Li is only $50 \%$ and that especially Mg makes the process unfavorable (Intaranont et al., 2014). An et al. (2012) have suggested an alternative process for brines having high $\mathrm{Mg}$ concentrations and some sulfate. Most of the $\mathrm{Mg}$ and $\mathrm{Ca}$ are precipitated with lime, $\mathrm{B}$ is adsorbed, and residual $\mathrm{Ca}$ and $\mathrm{Mg}$ are precipitated as oxalates. After these steps, evaporation and polishing purification (not described more closely) are still needed before $\mathrm{Li}_{2} \mathrm{CO}_{3}$ precipitation. Two patents by Boryta et al. (2002 and 2010) suggest the use of conventional cation exchangers to purify the brine solutions after the Ca and Mg precipitation steps. Bukowsky et al. (1991) used chelating resins to remove $\mathrm{Ca}$ and $\mathrm{Mg}$ from the brine, and Nishihama at al. (2011) purified the brine of divalent metals with a strong cation exchanger. For the B removal step, solvent extraction with some alcohol is suggested (Brown and Boryta, 1993). However, in these conventional processes, the removal efficiency, especially that for $\mathrm{Mg}$, in the final purification is not very high, and the Li losses are typically ten percent or higher.

The conventional precipitation purification containing processes are only able to produce $\mathrm{Li}_{2} \mathrm{CO}_{3}$ of 99.0-99.5\% purity (An et al., 2012; Moreno, 2013), which is suitable for ceramic applications, but, for example, in production of the Li-ion batteries, over $99.9 \%$ pure $\mathrm{Li}_{2} \mathrm{CO}_{3}$ is needed. Solvent extraction is known to produce high purity raffinates in many cases but purification of Li-rich brine with solvent extraction has received surprisingly little attention. The only research article is by Bukowsky et al. (1992). In that paper, D2EHPA was successfully used for the task, and the discussion was mainly regarding the equilibrium data for Ca.

In this work the above described known challenges (Li purity and losses) in the Li brine concentrate purification are studied by solvent extraction. In addition to $\mathrm{Ca}$ removal 
presented in the paper by Bukowsky et al. (1992), emphasis is also in the typical challenge of $\mathrm{Mg}$ removal. The performance of the suggested purification process step is also studied in bench-scale continuous counter-current experiments in mixer-settlers to demonstrate the applicability of the suggested flowsheet in industrial type equipment. The goal was to reduce the $\mathrm{Ca}$ and $\mathrm{Mg}$ concentrations from ca. $1.3 \mathrm{~g} / \mathrm{L}$ and $50 \mathrm{mg} / \mathrm{L}$, respectively, to under $20 \mathrm{mg} / \mathrm{L}$ or desirably to the ppm level if possible while having significantly lower Li losses than in conventional precipitation purification. First, a comparison of three types of commercial cation exchangers based on laboratory-scale experiments is presented. Based on these fundamental data, continuous experiments were designed and run to study process dynamics and performance.

\section{Experimental}

\subsection{Materials and reagents}

LIX-984 (1:1 mixture of 5-dodecylsalicylaldoxime and 2-hydroxy-5-nonylacetophenone oxime), D2EHPA (di-(2-ethylhexyl)phosphoric acid), and Versatic 10 (neodecanoic acid) were used as solvent extraction reagents, and prior to the experiments, they were analyzed via titrations, and their concentrations in all experiments were $0.50,0.52$, and $0.53 \mathrm{~mol} / \mathrm{L}$, respectively. Exxsol D80 (Exxon Mobil) and Shellsol D70 (Shell Chemicals) were used as diluents. Both of these are similar hydrocarbon fluids with very low aromatics content, and they are thus expected to have the same performance in the systems studied. Other chemicals used in the experimental work were: LiCl (supplier VWR International, purity 98\%), $\mathrm{CaCl}_{2}$ (VWR International, 98\%), $\mathrm{NaCl}$ (VWR International, 98\%), 
$\mathrm{MgCl}_{2} \cdot 4.5 \mathrm{H}_{2} \mathrm{O}$ (VWR International, 97\%), 37\% $\mathrm{HCl}$ (Merck KGaA, pro analysi), 65\% $\mathrm{HNO}_{3}$ (Merck KGaA, pro analysi), $25 \% \mathrm{NH}_{3}$ (Merck KGaA, pro analysi), $\mathrm{NaOH}$ (VWR International, 98\%), and ethanol (Merck KGaA, 99\%).

In all the experiments in this work, similar synthetic Li-rich brine solutions prepared with purified water were used as the feed aqueous phase. According to the analyses, their compositions were as follows: $\mathrm{Li} 26.0-34.0 \mathrm{~g} / \mathrm{L}, \mathrm{Ca} 1.17-1.55 \mathrm{~g} / \mathrm{L}, \mathrm{Mg}$ 0.022-0.075 g/L. The total chloride concentration was topped up to $200 \mathrm{~g} / \mathrm{L}$ with $\mathrm{NaCl}$, and the $\mathrm{pH}$ was 7.5. All metal analyses, both from the batch experiments and pilot runs, were carried out from $14 \% \mathrm{HNO}_{3}$-media using inductively coupled plasma atomic emission spectroscopy (ICPAES, device: IRIS Intrepid Duo, Thermo Electron Corporation). The organic phase metal concentrations were analyzed after stripping them with $14 \% \mathrm{HNO}_{3}(\mathrm{~A} / \mathrm{O}=10: 1)$.

\subsection{Equilibrium and kinetic experiments}

The effect of $\mathrm{pH}$ on the extent of $\mathrm{Ca}, \mathrm{Mg}$, and Li extraction from the brines with D2EHPA, Versatic 10, and LIX-984 was studied in a jacketed $1000 \mathrm{~mL}$ glass reactor at 23 and $35^{\circ} \mathrm{C}$. The $\mathrm{pH}$ of the aqueous phase was adjusted by bubbling ammonia gas with nitrogen into the reactor, and before sampling, the mixing was continued for 15 min to ensure equilibrium. The aqueous phases were analyzed to construct the $\mathrm{Ca}$ and $\mathrm{Mg}$ isotherms. The

$\mathrm{Li}$ isotherm was constructed based on the organic phase analysis because the $\mathrm{Li}$ concentration in the aqueous phase was very high, and thus, relatively small extracted amounts were more accurately detected from the organic phase. The extent of extraction for metal i, $E_{\mathrm{i}}$, was used to represent the effectiveness of the solvent extraction (Eq. 1). 


$$
E_{\mathrm{i}}=\frac{\overline{c_{\mathrm{i}}}}{c_{\mathrm{i}}^{\text {feed }}} \frac{V_{\text {org }}}{V_{\text {aq }}} \cdot 100 \%=\frac{c_{\mathrm{i}}^{\text {feed }}-c_{\mathrm{i}}}{c_{\mathrm{i}}^{\text {feed }}} \cdot 100 \%
$$

The bars above the concentrations stand for the organic phase, $c^{\text {feed }}$ is the initial concentration in the aqueous phase, and $V_{\text {org }}$ and $V_{\text {aq }}$ are the volumes of the organic and aqueous phases, respectively. The loading isotherms for $\mathrm{Ca}$ and $\mathrm{Mg}$ were constructed for D2EHPA at equilibrium $\mathrm{pH}$ values of 3.5 and 3.9, and for Versatic 10 at equilibrium $\mathrm{pH}$ values of 7.0 and 8.0. The values were chosen based on the $\mathrm{pH}$ isotherms, which were constructed as described above. The experiments were performed at $35^{\circ} \mathrm{C}$ in a $120 \mathrm{~mL}$ jacketed glass reactor. The metals from both phases were analyzed. The overall extraction kinetics in extraction of metals from the brine was studied in jacketed $80 \mathrm{~mL}$ glass reactors at $35{ }^{\circ} \mathrm{C}$. The phase ratio A/O in the reactor was $1: 1.61 \%$ saponified D2EHPA and $50 \%$ saponified Versatic 10 were used as extractants, yielding pHs of 4.1 and 8.1, respectively, after 10 min of contact time, which was the duration of the experiments.

\subsection{Continuous counter-current experiments}

Continuous counter-current solvent extraction for the purification of Li-rich brine was performed in bench-scale pilot equipment (provided by SX Kinetics Inc.). A schematic of the setup with two counter-current stages is presented in Fig. 1. D2EHPA and Versatic 10 were used as reagents in these continuous runs. The mixers had a volume of $270 \mathrm{~mL}$, and the settlers were jacketed $1050 \mathrm{~mL}$ vessels. Peristaltic MasterFlex pumps (model 0752830) were used for feeding the aqueous and organic phases. Semi-open six-bladed impellers with rotation speeds of 700-900 rpm were used for agitation. The temperature and $\mathrm{pH}$ of the mixers were monitored in real-time. The temperatures were adjusted via a water bath 
connected to the jackets of the settlers, and the $\mathrm{pH}$ was adjusted via the appropriate saponification of the reagents with either aqueous $25 \% \mathrm{NH}_{3}$ or $5 \mathrm{M} \mathrm{NaOH}$. The phase ratios were adjusted by recycling the stream of the organic phase from a settler into the mixer of the same stage, and they were monitored by sampling next to the impeller. For chemical analyses, in order to monitor the actual behavior of the purification, samples were taken from outlet of each stage several times during the run.

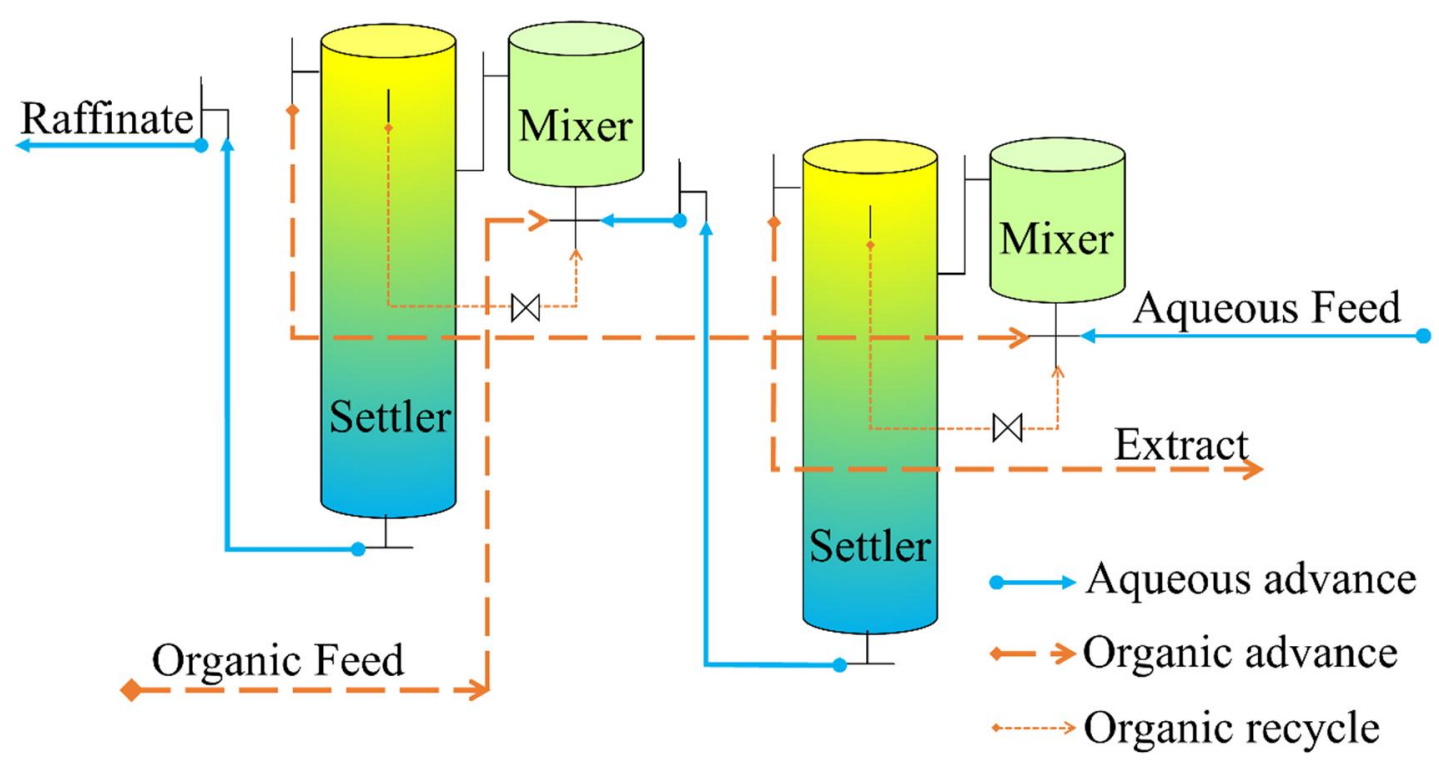

Figure 1. Continuous counter-current solvent extraction mixer-settler setup for studying the purification of Li-rich brine.

In this study, the process configuration in every run contained two extraction stages and one stripping stage. The details of the run parameters are given in Table 1, in Section 3.2, along with the results. The residence time in the mixer was varied between 2.0 and 6.1 min, and the $\mathrm{A} / \mathrm{O}$ phase ratio varied between 1.5 and 0.6 . With D2EHPA, the $\mathrm{pH}$ in the mixers varied between 3.7 and 4.1, and with Versatic 10, it varied between 6.2 and 7.4. The temperature in the mixers was elevated to at least $31.0^{\circ} \mathrm{C}$, except in one run with 
Versatic 10 , in which a room temperature of $23.0^{\circ} \mathrm{C}$ was used. The run time was 180 $360 \mathrm{~min}$, and the flowrates were $20-74 \mathrm{~mL} / \mathrm{min}$ and $20-84 \mathrm{~mL} / \mathrm{min}$ for the aqueous and organic phases, respectively. Thus, 50-120 times the mixer volume of the aqueous feed was treated in each run, and from the chemical analyses, it was observed that the process was at a steady-state in every run.

\section{Results and discussion}

\subsection{Equilibrium and kinetic studies for designing the continuous experiments}

The experimental $\mathrm{pH}$ isotherms for D2EHPA, Versatic 10 and LIX-984 are displayed in Fig. 2. Of the reagents studied here, D2EHPA extracted $\mathrm{Ca}$ and $\mathrm{Mg}$ from the Li-rich brines at the highest acid concentration, starting from $\mathrm{pH}$ less than 1 for $\mathrm{Ca}$ and from approximately $\mathrm{pH} 2$ for $\mathrm{Mg}$ at $35{ }^{\circ} \mathrm{C}$. With Versatic 10 , extraction was significant at $\mathrm{pH}$ higher than 5 and 6.5 for $\mathrm{Ca}$ and $\mathrm{Mg}$, respectively. With LIX-984, $\mathrm{Mg}$ was extracted at $\mathrm{pH}$ higher than 8 , whereas only $29 \%$ extraction was achieved for Ca before undesired phase changes began occurring at a $\mathrm{pH}$ of 9.0. Using hydroxyoxime reagents in alkaline conditions is not possible, because they are saponified, which increases their solubility in the aqueous phase (Preston and Whewell, 1977; Szymanowski, 1993).

D2EHPA has the strongest affinity for $\mathrm{Ca}$ and $\mathrm{Mg}$ of the reagents studied, and it also gives highest $\mathrm{Ca} / \mathrm{Mg}$ selectivity. However, regarding the set goals for the solvent extraction purification, both of the metals must be removed, and having the Mg isotherm closer to the $\mathrm{Ca}$ isotherm would actually improve the selectivity over $\mathrm{Li}$. A high $\mathrm{Ca} / \mathrm{Mg}$ selectivity is thus not a desired property here. As observed in Fig. 2, extraction of $\mathrm{Mg}$ is complete at $\mathrm{pH}$ 
5 where extraction of $\mathrm{Li}$ is already significant (approximately 10\%), which means that D2EHPA actually shows the lowest selectivity in the removal of impurities from Li.

On the other hand, with Versatic 10, the $\mathrm{Ca}$ and $\mathrm{Mg}$ isotherms are closer, the $\mathrm{pH}$ isotherm of $\mathrm{Mg}$ is steeper, and the $\mathrm{Li}$ isotherm is more gradual as compared to D2EHPA. The costs of $\mathrm{pH}$ adjustment do not play a significant role in the comparison of the reagents, because the working range for all of them would be in the neutral, only slightly acidic, or alkaline range ( $\mathrm{pH} 3.5$ to 9 ) and the $\mathrm{pH}$ of the feed was 7.5 .

The influence of temperature on $\mathrm{pH}$ isotherms was studied with D2EHPA. Decreasing the temperature from 35 to $23{ }^{\circ} \mathrm{C}$ increased the selectivity between $\mathrm{Ca}$ and $\mathrm{Mg}$ by shifting the $\mathrm{Ca}$ isotherm towards a lower $\mathrm{pH}$ and the $\mathrm{Mg}$ isotherm towards a higher $\mathrm{pH}$ (Fig. 2). This effect is not desirable, because the Li isotherm remained in the same place, thus decreasing $\mathrm{Mg} / \mathrm{Li}$ selectivity. The $\mathrm{pH}$ isotherm data suggests that Versatic 10 would be the best choice for Li-brine purification, but this alone is not sufficient for selection of the reagent for a continuous multistage counter-current purification process as the loading capacity of the reagent plays also a significant role.

For the following loading isotherms, two $\mathrm{pH}$ values for both reagents were chosen so that the competing effects could be observed. The chosen values were 3.5 and 3.9 for D2EHPA, and 7.0 and 8.0 for Versatic 10. 

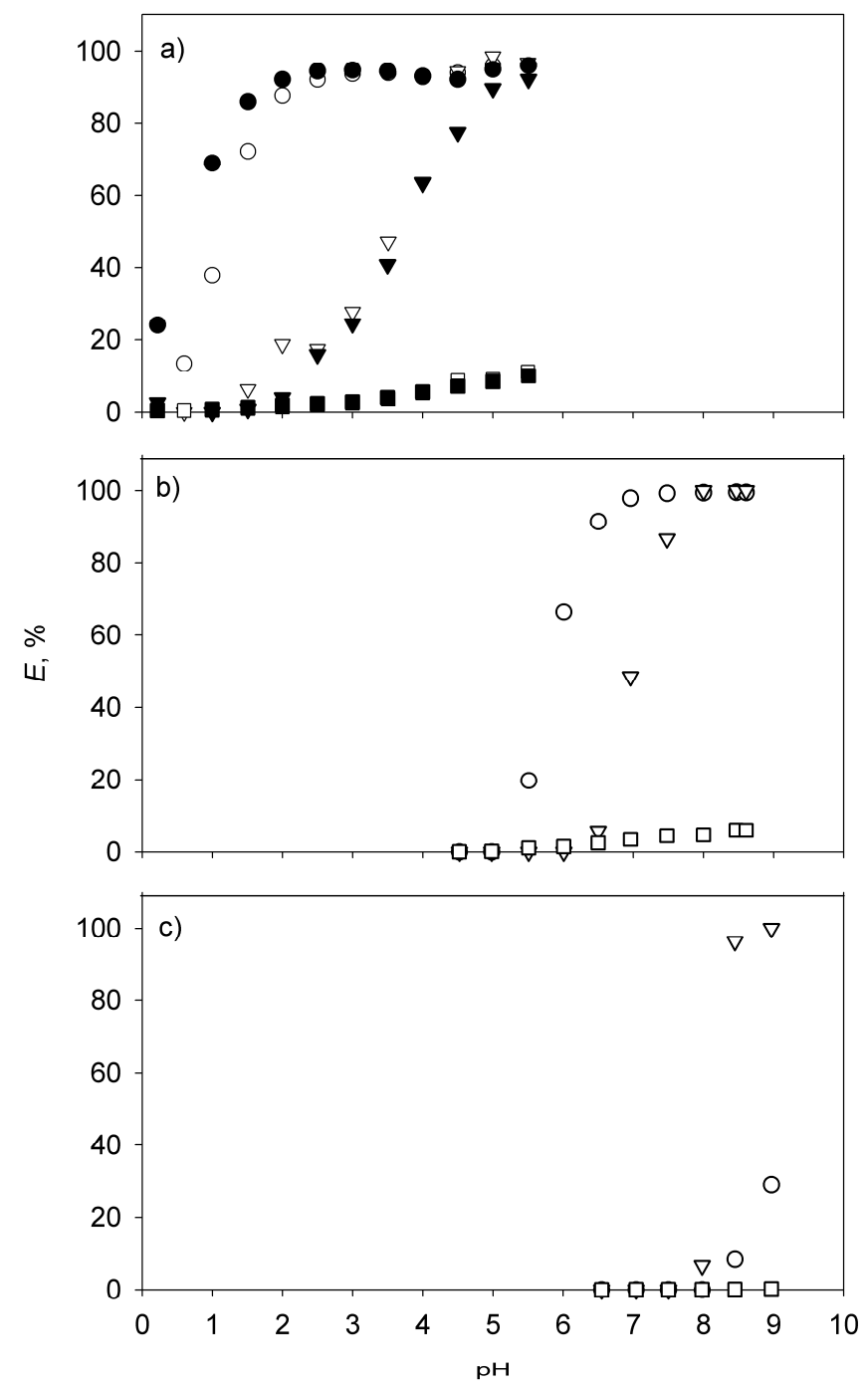

Figure 2. The dependence of the metal extraction on $\mathrm{pH}$ with certain commercial solvent extraction reagents in the purification of Li-rich brine. The initial concentrations of the metals were $\mathrm{Li} 26.0 \mathrm{~g} / \mathrm{L}, \mathrm{Ca} 1.30 \mathrm{~g} / \mathrm{L}$, and $\mathrm{Mg} 0.022 \mathrm{~g} / \mathrm{L}$, and reagent concentrations were $0.52,0.53$, and $0.50 \mathrm{~mol} / \mathrm{L}$ for D2EHPA, Versatic 10 and LIX-984, respectively. a): D2EHPA, b) Versatic 10, and c) LIX-984. Circles $\mathrm{Ca}$, triangles $\mathrm{Mg}$, and squares Li. Open symbols $35^{\circ} \mathrm{C}$, and closed symbols $23{ }^{\circ} \mathrm{C}$.

The much stronger affinity on the part of $\mathrm{Ca}$ as compared to $\mathrm{Mg}$ for both D2EHPA and Versatic 10 can be also seen from the experimental loading isotherms shown in Figs. 3 and 4. For D2EHPA, the Ca isotherms are not very steep, but the capacity rises to nearly $4 \mathrm{~g} / \mathrm{L}$ at aqueous concentrations of $1 \mathrm{~g} / \mathrm{L} \mathrm{Ca}$ at both $\mathrm{pH} 3.5$ and 3.9, used here. However, at $\mathrm{pH}$ 
3.9, the organic phase can be loaded only up to $3.3 \mathrm{~g} / \mathrm{L}$, after which the co-extraction of $\mathrm{Li}$ causes the organic phase become too viscous for practical operation. The $\mathrm{Ca}$ isotherms are steeper with Versatic 10 than with D2EHPA, but the capacities at an aqueous concentration of $1 \mathrm{~g} / \mathrm{L}$ were only 2.7 and $3.3 \mathrm{~g} / \mathrm{L}$ at $\mathrm{pHs}$ of 7.0 and 8.0 , respectively.

The extraction of $\mathrm{Mg}$ from the multimetal brine was not efficient, though it was possible, with both extractants at the pHs studied in the loading isotherm experiments (Fig. 4). This is because Ca clearly forces $\mathrm{Mg}$ out from the organic phase at high loadings. For three of the four isotherms displayed in Fig. 4, the Mg loading curve passes through a maximum, and the $\mathrm{Mg}$ loadings are very low when the total concentration $(\mathrm{Ca}+\mathrm{Mg})$ in the aqueous phase is high. Also, the maximum loading levels were low: 16 and $24 \mathrm{mg} / \mathrm{L}$ (equilibrium $\mathrm{pH} 3.5$ and 3.9) with D2EHPA and 21 and $36 \mathrm{mg} / \mathrm{L}$ (equilibrium $\mathrm{pH} 7.0$ and 8.0) with Versatic 10. With D2EHPA, at a $\mathrm{pH}$ of $3.9, \mathrm{Mg}$ saturation was not achieved, but as discussed above, the organic phase cannot be more loaded with this particular brine solution, because the co-extraction of Li causes undesired phase changes.

In Figs. 3 and 4, in addition to the loading isotherms, the operating lines of the countercurrent mixer-settler cascade with phase ratios $\mathrm{A} / \mathrm{O}=1: 1$ and $0.6: 1$ and zero raffinate concentrations of impurities are given. Even without solving the compositions of the stages via the mass balances, it can clearly be seen that elimination of $\mathrm{Ca}$ would not be a problem in counter-current operation at sufficiently close to phase equilibrium conditions. Ca could be removed to the ppm level with D2EHPA in two stages, and with Versatic 10, this could be done in just one stage at both equilibrium pHs. Though the Ca uptake of D2EHPA is higher than that of Versatic 10, the steeper beginning of the loading curve of Versatic 10 makes it a more efficient reagent. This is because the equilibrium point of the first 
extraction stage should not be at very high loading so that $\mathrm{Mg}$ will not be rejected from the organic phase due to its high saturation with $\mathrm{Ca}$.

In order to achieve sufficiently high $\mathrm{Mg}$ removal, the $\mathrm{pH}$ must be carefully controlled and either the extractant concentration or amount of organic phase in the mixer should be high enough (lower A/O) as well. With the systems studied, with extractant concentrations of $0.52-0.53 \mathrm{~mol} / \mathrm{L}$, inefficient $\mathrm{Mg}$ removal is expected with a phase ratio $\mathrm{A} / \mathrm{O}=1: 1$ and two extraction stages when the $\mathrm{pH}$ is 3.5 with D2EHPA and 7.0 with Versatic 10. Lowering the phase ratio $\mathrm{A} / \mathrm{O}$ to 0.6 should increase $\mathrm{Mg}$ removal so that the concentration in the raffinate is at the ppm level. With D2EHPA at $\mathrm{pH} 3.9$ and with Versatic 10 at $\mathrm{pH} 8.0, \mathrm{Mg}$ removal to the ppm level could also be accomplished with a higher phase ratio $(\mathrm{A} / \mathrm{O}=1: 1)$, and with Versatic 10, even operating with only one extraction stage could be possible.

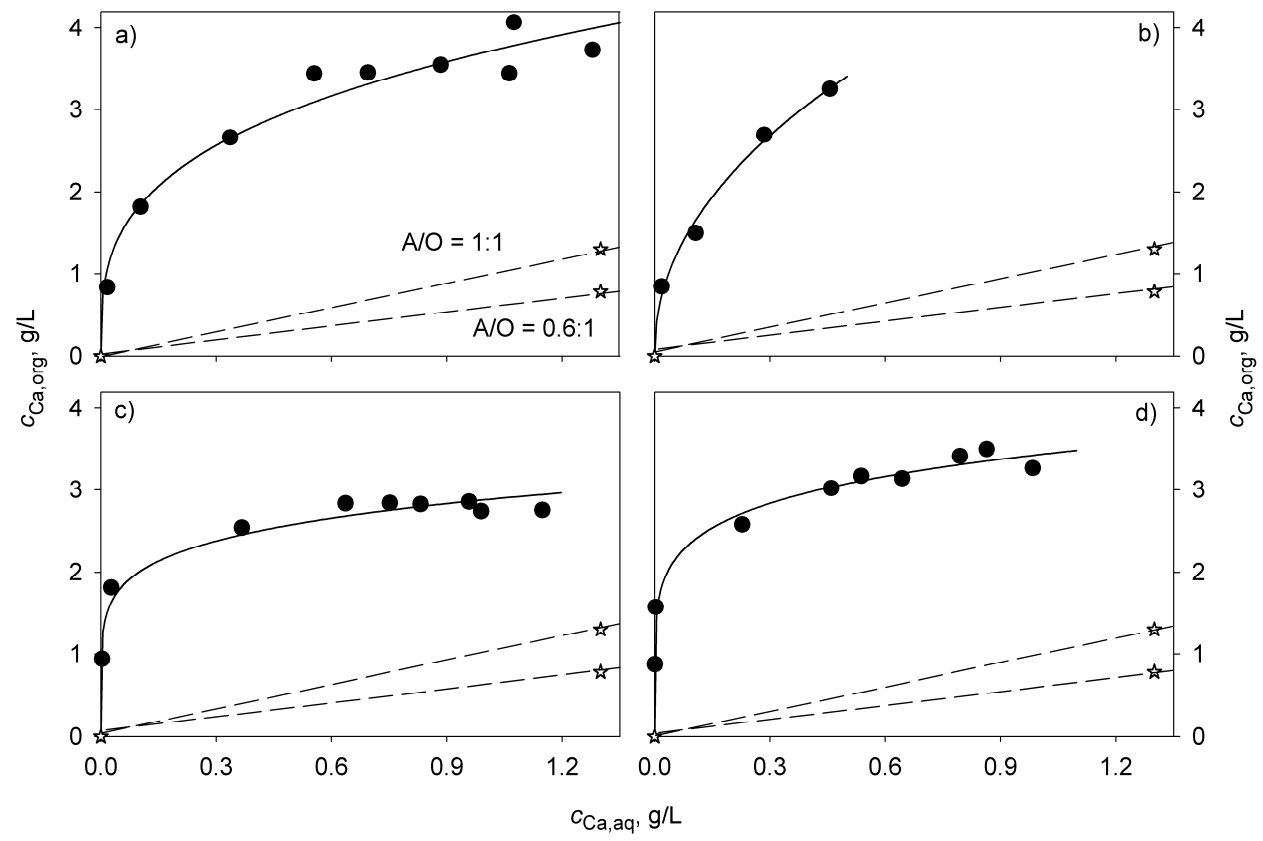

Figure 3. Loading isotherms (circles) of Ca for D2EHPA (a: $\mathrm{pH} 3.5$, b: $\mathrm{pH}$ 3.9) and Versatic 10 (c: $\mathrm{pH} 7.0, \mathrm{~d}: \mathrm{pH}$ 8.0) from Li-rich brine. The solid lines with the isotherms are empirical fits used to better visualize the trends. The dashed lines and stars represent the operating lines for the brine. The reagent concentrations were 0.52 and $0.53 \mathrm{~mol} / \mathrm{L}$ for D2EHPA and Versatic 10 respectively. 

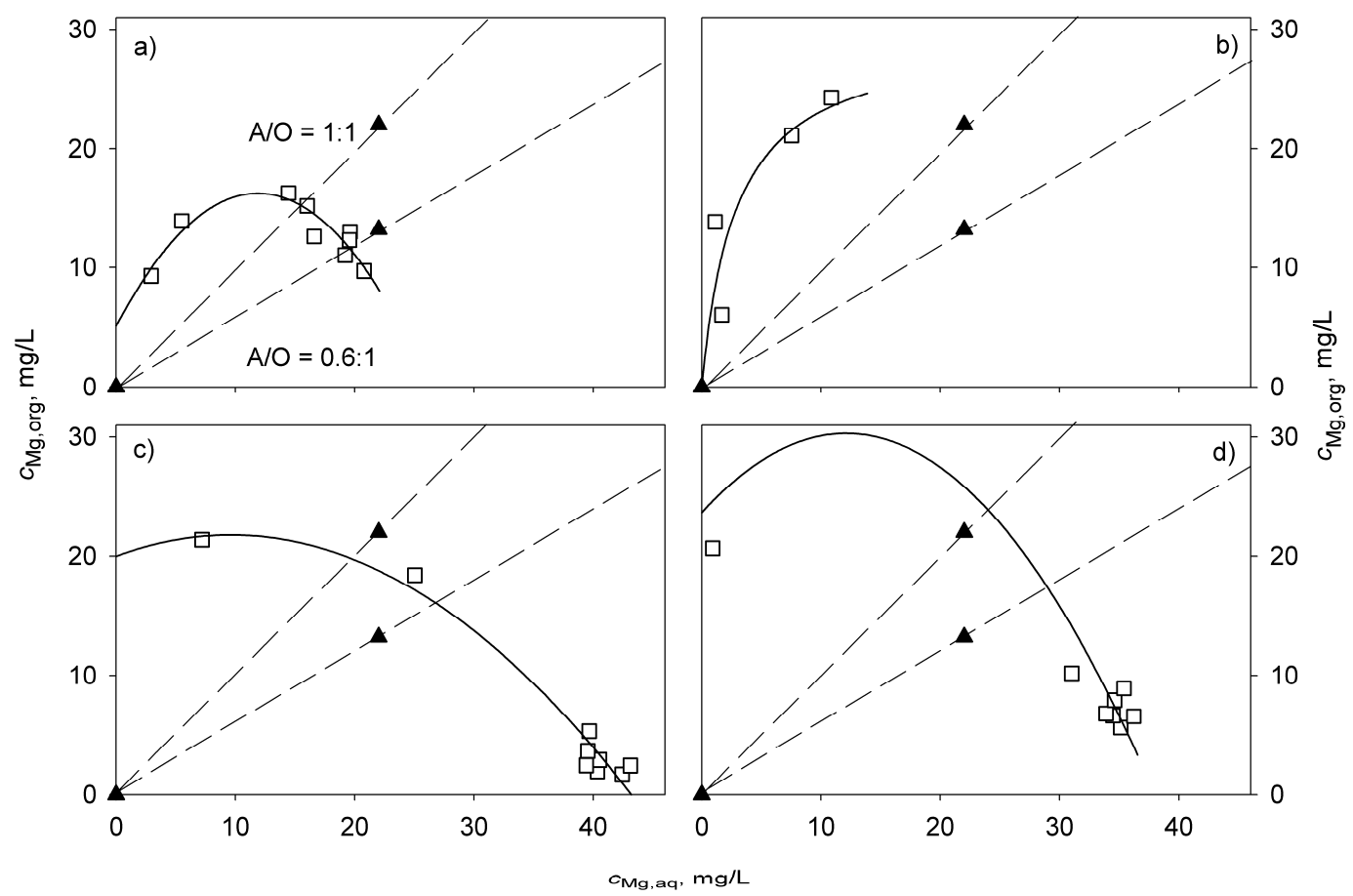

Figure 4. Loading isotherms of Mg (squares) for D2EHPA (a: $\mathrm{pH} 3.5, \mathrm{~b}: \mathrm{pH} 3.9$ ) and Versatic 10 (c: $\mathrm{pH} 7.0, \mathrm{~d}: \mathrm{pH}$ 8.0) from Li-rich brine. The solid lines with the isotherms are empirical fits used to better visualize the trends. The dashed lines and triangles represent the operating lines for the brine. The reagent concentrations were 0.52 and $0.53 \mathrm{~mol} / \mathrm{L}$ for D2EHPA and Versatic 10 respectively.

$\mathrm{Ca}$, which has the strongest binding to D2EHPA and Versatic 10, also exhibits the fastest kinetics (Fig. 5). The extent of extraction in a well-agitated batch reactor is at the maximum $($ Versatic $10=100 \%$, D2EHPA $=98 \%)$ after only 30 s of contact. Li extraction seems to be close to its equilibrium after only 5 min for both of the reagents, though in the data regarding D2EHPA, there is some fluctuation due to the inaccuracy of the analysis. The extraction of Li also seems to push a small amount of $\mathrm{Mg}$ out of both of the reagents. The extents of extraction were at the maximum after $30 \mathrm{~s}$ for both reagents (Versatic $10=87 \%$, D2EHPA $=81 \%$, and after 10 min of contact time, they had decreased to $86 \%$ and $78 \%$, respectively. These results indicate that the undesired co-extraction of Li could be reduced 
by adjusting contact time and, at the same time, the removal of $\mathrm{Mg}$ could be slightly improved. However, it should be noted that the apparent kinetics experiments were made in a batch reactor; thus, the actual times are not directly transferable to a bench-scale counter-current operation, in which the reactor type is a continuous stirred-tank reactor (CSTR).

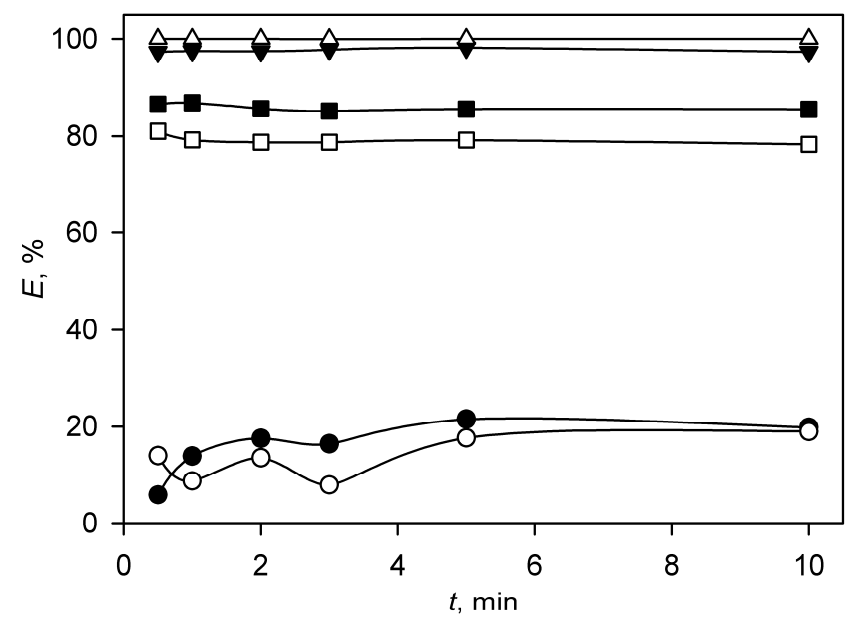

Figure 5. Effect of contact time in batch reactor on solvent extraction of $\mathrm{Ca}, \mathrm{Mg}$, and $\mathrm{Li}$ from Li-rich brine with D2EHPA and Versatic 10 reagents. The initial concentrations of the metals were $\mathrm{Li} 28.5 \mathrm{~g} / \mathrm{L}, \mathrm{Ca} 1.3 \mathrm{~g} / \mathrm{L}$, and $\mathrm{Mg} 0.039 \mathrm{~g} / \mathrm{L}$, and the reagent concentrations were 0.52 and $0.53 \mathrm{~mol} / \mathrm{L}$ for D2EHPA and Versatic 10, respectively. Triangles $\mathrm{Ca}$, squares $\mathrm{Mg}$, and circles Li.

\subsection{Continuous counter-current processing}

As concluded in the previous section, the batch equilibrium and kinetics data indicate that Versatic 10 and D2EHPA are both viable reagent candidates for the purification of Li-rich brine. Because Versatic 10 was found to be somewhat better in terms of lower Li coextraction, its use was investigated in more detail in the continuous counter-current runs. LIX-984 was found to be unfeasible for this separation task due to its limited $\mathrm{pH}$ range and 
was thus excluded from the continuous runs. The actual run parameters varied were $\mathrm{pH}$, phase ratio $\mathrm{A} / \mathrm{O}$, and residence time $\tau$. The details of the run parameters are given, together with the results, in Table 1.

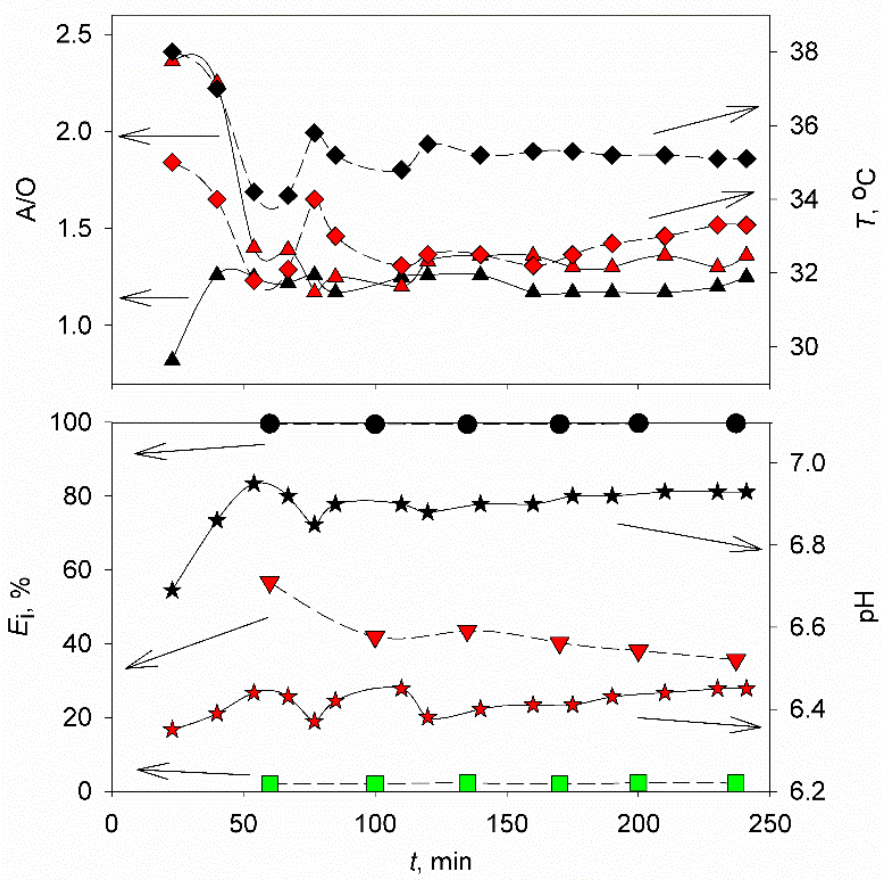

Figure 6. Trends for the run parameters in a typical run for the purification of $\mathrm{Ca}$ and $\mathrm{Mg}$ from Li-rich brine via continuous counter-current solvent extraction. The run depicted is Run id. V-4 in Table 1. The concentrations of metals in the feed solution were $\mathrm{Li} 28 \mathrm{~g} / \mathrm{L}, \mathrm{Ca} 1.35 \mathrm{~g} / \mathrm{L}$, and $\mathrm{Mg} 0.059 \mathrm{~g} / \mathrm{L}$, and the concentration of Versatic 10 was $0.53 \mathrm{~mol} / \mathrm{L}$. Triangles up $\mathrm{A} / \mathrm{O}$, diamonds $T$, stars $\mathrm{pH}$, and circles, triangles down and squares extents of extraction for $\mathrm{Ca}, \mathrm{Mg}$, and $\mathrm{Li}$, respectively. Black symbols refer to the first stage counting from the aqueous feed. 
Table 1. Details and results of the continuous counter-current solvent extraction bench-scale experiments for the purification of Ca and $\mathrm{Mg}$ from Li-rich brine. The $\mathrm{pHs}$ and extents of extraction $\left(E_{\mathrm{i}}\right)$ are average values over the run. The temperatures and phase ratios are average values over the entire run and the two loading stages. The feed solutions contained 26.0-34.0 g/L $\mathrm{Li}, 1.14-1.55 \mathrm{~g} / \mathrm{L} \mathrm{Ca}$ and 0.045-0.075 g/L Mg. In run id., D stands for D2EHPA, and V stands for Versatic 10.

\begin{tabular}{|c|c|c|c|c|c|c|c|c|c|}
\hline Run id. & $\begin{array}{l}\text { pH } 1^{\text {st }} \\
\text { stage }\end{array}$ & $\begin{array}{l}\text { pH } 2^{\text {nd }} \\
\text { stage }\end{array}$ & $T,{ }^{\circ} \mathbf{C}$ & $\begin{array}{l}\text { Phase ratio } \\
\text { A/O }\end{array}$ & $\tau$, min & $\begin{array}{l}\text { Reactor } \\
\text { volumes of } \\
\text { feed }\end{array}$ & $E_{\text {Ca }}, \%$ & $E_{M g}, \%$ & $E_{\mathrm{Li}}, \%$ \\
\hline D-1 & 3.9 & 4.1 & 31.0 & 0.85 & 6.0 & 50 & 99 & 94 & 9.1 \\
\hline D-2 & 3.7 & 3.6 & 33.5 & 1.25 & 6.1 & 59 & 99 & 90 & 4.0 \\
\hline D-3 & 3.7 & 3.8 & 31.0 & 1.20 & 2.0 & 90 & 98 & 86 & 5.3 \\
\hline V-1 & 6.7 & 7.1 & 36.0 & 1.00 & 4.5 & 67 & 100 & 95 & 4.6 \\
\hline V-2 & 6.2 & 6.8 & 35.0 & 1.25 & 6.1 & 52 & 97 & 34 & 1.4 \\
\hline V-3 & 6.9 & 7.4 & 23.0 & 1.35 & 6.0 & 67 & 99 & 50 & 2.1 \\
\hline$V-4$ & 6.4 & 6.9 & 34.0 & 1.25 & 2.0 & 120 & 99 & 40 & 2.1 \\
\hline V-5 & 6.6 & 6.9 & 32.5 & 0.60 & 5.1 & 71 & 100 & 90 & 3.3 \\
\hline V-6 & 6.4 & 6.9 & 34.0 & 0.60 & 2.0 & 115 & 100 & 98 & 5.5 \\
\hline
\end{tabular}


The typical continuous counter-current run lasted around 240 min (Fig. 6), of which the first 60-120 min went to adjusting and stabilizing the run parameters and conditions (the temperature and the phase ratio). Although the $\mathrm{pH}$ was not controlled, it changed only in the beginning of the run and settled to constant a value as the run approached the steadystate. Ca uptake and the co-extraction of Li leveled off rather quickly, but Mg-removal efficiency typically took longer to reach the steady-state. This is because it has the lower affinity than $\mathrm{Ca}$ to the Versatic 10 extractant, and thus, due to the competing effect, it can be displaced from the organic phase in the first extraction stage and extracted in the second one (Fig. 7). This complicated migration behavior of the $\mathrm{Mg}$ around the continuous counter-current system causes the concentration changes in the raffinate to take place slower.

\section{Effect of $\mathrm{pH}$ and phase ratio on performance}

The effect of increasing the $\mathrm{pH}$ and, at the same time, decreasing the phase ratio $\mathrm{A} / \mathrm{O}$ can be seen by comparing runs D-1 and D-2 (Table 1). Together, these changes cause higher extents of extractions for both $\mathrm{Mg}$ and $\mathrm{Li}$. It is thus concluded that there is no such combination of these parameters that would allow ca. $100 \%$ yield for $\mathrm{Mg}$ while extracting

practically no Li. Both of these goals could be achieved separately, but only at the cost of lower performance in relation to the other.

Similar behavior is observed also with Versatic 10 (compare runs V-1 and V-2 in Table 1). However, in the latter run, the phase ratio $\mathrm{A} / \mathrm{O}$ was higher, meaning that the system was working near saturation, thus leaving less space for the $\mathrm{Mg}$ and $\mathrm{Li}$. It can be also observed 
from runs $\mathrm{V}-5$ and $\mathrm{V}-6$ that when the $\mathrm{A} / \mathrm{O}$ was low, the $\mathrm{Mg}$ and Li removals were high, even though the $\mathrm{pH}$ was 6.4-6.6 in the first stage and 6.9 in the second one.

The competition of $\mathrm{Ca}$ and $\mathrm{Mg}$ can also be seen by studying the concentration profiles of the metals along the continuous counter-current system (Fig. 7). The first extraction stage, counting from the aqueous feed, removes as much $\mathrm{Ca}$ as it can. This means that it may also actually replace some $\mathrm{Mg}$ from the organic phase if the equilibrium is near the saturation of the reagent. However, this effect was removed when the amount of organic phase in the mixer was increased from run $\mathrm{V}-4$ to $\mathrm{V}-6$, and then also the first extraction stage removed $\mathrm{Mg}$. The second extraction stage then removes the rest of the $\mathrm{Ca}$ and as much $\mathrm{Mg}$ as it can.

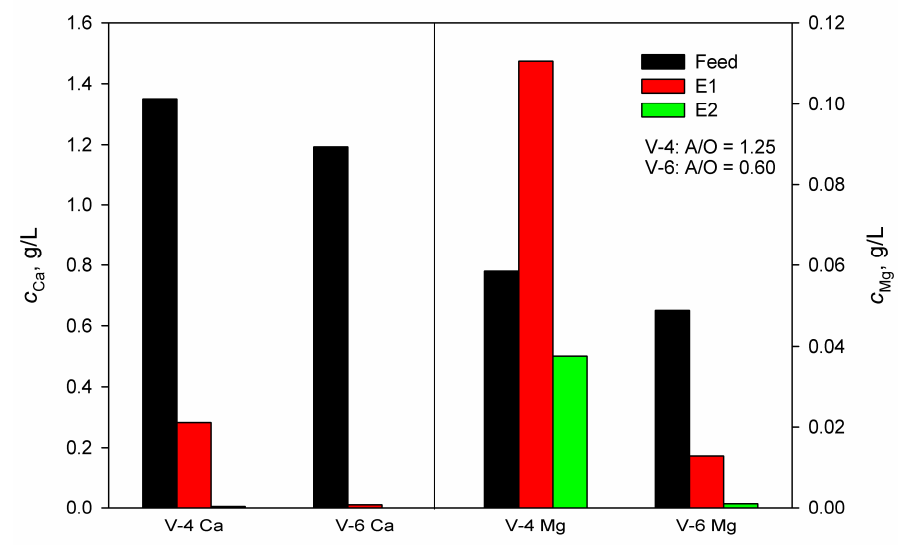

Figure 7. Steady-state concentrations of metals in the aqueous phase across the continuous two-stage counter-current solvent extraction unit during the purification of Li-rich brine. The runs included here are V-4 and V-6 (see Table 1).

\section{Effect of temperature on performance}

By comparing the V-2 and V-3 runs, it can be seen that the temperature does not have much effect (Table 1). The extraction efficiencies of all the metals were slightly higher at the lower temperature $\left(23.0^{\circ} \mathrm{C}\right)$, but at least with $\mathrm{Mg}$ and $\mathrm{Li}$, this was probably only due to a 
slightly higher $\mathrm{pH}$ (6.9 and 7.4 as compared to 6.2 and 6.8). With $\mathrm{Ca}$, the increment in the extent of extraction from 97 to $99 \%$ is most probably due to the decreasing temperature because a small increase in $\mathrm{pH}$ should not have an effect on Ca extraction in such a high $\mathrm{pH}$ range.

\section{Effect of residence time on performance}

Decreasing the residence time (in the mixer) with Versatic 10 from 5.1 to $2.0 \mathrm{~min}$ increased both $\mathrm{Mg}$ and Li extractions (Table 1, runs V-5 and V-6). In contrast with the batch kinetics data (see Fig. 5), decreasing Mg extraction with increasing residence time in the continuous runs cannot be explained by Li partly replacing it. With D2EHPA, the performance in terms of both $\mathrm{Mg}$ removal and $\mathrm{Li}$ co-extraction was actually a bit worse with a shorter residence time. Therefore, the possibility of affecting the performance by optimizing the residence time could not be confirmed with these bench-scale data. However, it can be concluded that with the run configuration used here, a residence time (in the mixer) of two minutes or even shorter yields high purity and throughput for the brine.

\section{Stripping behavior}

Stripping was included in the setup as one stage with $\mathrm{A} / \mathrm{O}=$ ca. 1:3. The acid concentrations were 3.0 and $2.0 \mathrm{M} \mathrm{HCl}$, respectively, for D2EHPA and Versatic 10. In every stripping sample of every run, the stripping was complete (the results are not shown). Although minimizing the usage of $\mathrm{HCl}$ was out of the scope of this research, for industrialscale operation, this should be done because its effect on costs would be significant. 


\section{Summary of continuous runs}

Overall, the results from all of the D2EHPA runs were satisfactory (Table 1). Ca was removed with at least $98 \%$ efficiency to $23 \mathrm{mg} / \mathrm{L}, \mathrm{Mg}$ was removed with $86 \%$ efficiency to $6.3 \mathrm{mg} / \mathrm{L}$, and $9.1 \%$ of $\mathrm{Li}$ was co-extracted at most. The purities of the Li raffinates were 99.9\%, while in the feed, they were 95.1-96.2\%. With Versatic 10, there was also runs with bad $\mathrm{Mg}$ purification performance because Li co-extraction was minimized. Runs $\mathrm{V}-1$, V5, and V-6 yielded over $99.9 \%$ brine raffinate purity, starting from $95.4-96.6 \%$ in the feed, while the Li co-extraction was 3.3-5.5\%. There was no $\mathrm{Ca}$ at all in the raffinate in these runs, and $5.3 \mathrm{mg} / \mathrm{L}$ of $\mathrm{Mg}$ at most.

The observations made based on the equilibrium experiments regarding the reagents' performance were corroborated in the bench-scale run results. A higher loading capacity for D2EHPA resulted in better purification performance in higher phase ratios (runs D-2 and V-4). On the other hand, a better selectivity on the part of Versatic 10 for divalent metals over Li can been seen by comparing runs D-1 and V-1.

\section{Conclusions}

The goal was to suggest a process in which the removal of $\mathrm{Ca}$ and $\mathrm{Mg}$ would be maximized while Li co-extraction would be minimized. Based on the laboratory scale equilibrium experiments following conclusions were made:

- LIX-984 is not suitable due to its saponification in the operational pH range.

- D2EHPA and Versatic 10 are viable candidates. D2EHPA had slightly higher affinity for all the metals $(\mathrm{Ca}, \mathrm{Mg}, \mathrm{Li})$, but Versatic 10 had better selectivity over Li.

- Operational pH ranges are 3.5-4.0 for D2EHPA, and 6.5-8.0 for Versatic 10. 
- The system should not be operated at saturation of the reagent, because then $\mathrm{Ca}$ replaces some of the extracted $\mathrm{Mg}$.

Based on the equilibrium data analysis, for both reagents two-stage loading with $\mathrm{A} / \mathrm{O}=0.6-1.3$ was chosen as the process set-up for the bench-scale experiments. Based on the experiments following conclusions were made:

- $99-100 \%$ of $\mathrm{Ca}$ and $>90 \%$ of $\mathrm{Mg}$ was removed yielding respectively $20 \mathrm{mg} / \mathrm{L}$ and $7 \mathrm{mg} / \mathrm{L}$ concentrations in the purified brine.

- Purity increase was from ca. $95 \%$ to $99.9 \%$ with under $5.5 \%$ Li losses.

- 5-6 min of residence time in the mixer is sufficient, but even 2 min would be enough.

As a final conclusion it can be stated that the studied solvent extraction process, with either reagent (D2EHPA or Versatic 10), is an attractive option for the purification of Li-rich brines. The goals of having ppm levels of $\mathrm{Ca}$ and $\mathrm{Mg}$ impurities in the treated brine were achieved, and the resulting $99.9 \%$ Li purity in the brine would be suitable for precipitating $\mathrm{Li}_{2} \mathrm{CO}_{3}$, from which battery-grade Li metal could be made.

Acknowledgements

Outotec (Finland) Oyj and particularly Mr. Marko Limnell are acknowledged for their support during the research.

\section{References}

An, J.W., Kang, D.J., Tran, K.T., Kim, M.J., Lim, T., Tran, T., 2012. Recovery of lithium from Uyuni salar brine. Hydrometallurgy 117-118, 64-70. doi:10.1016/j.hydromet.2012.02.008

Boryta, D.A., Kullberg, T.F., Thurston, A.M., 2010. Production of lithium compounds directly from lithium containing brines. US7858057 B2.

Boryta, D.A., Kullberg, T.F., Thurston, A.M., 2002. Recovery of lithium compounds from brines. US6497850 B1. 
Brown, P.M., Boryta, D.A., 1993. Production of low boron lithium carbonate from lithiumcontaining brine. US5219550 A.

Bukowsky, H., Uhlemann, E., Steinborn, D., 1991. The recovery of pure lithium chloride from "brines" containing higher contents of calcium chloride and magnesium chloride. Hydrometallurgy 27, 317-325. doi:10.1016/0304-386X(91)90056-R

Bukowsky, H., Uhlemann, E., Gloe, K., Mühl, P., 1992. The separation of calcium and magnesium from lithium chloride by liquid-liquid extraction with di (2-ethylhexyl) phosphoric acid. Hydrometallurgy 28, 323-329. doi:10.1016/0304-386X(92)90037$\mathrm{Z}$

Cabeza, L.F., Gutierrez, A., Barreneche, C., Ushak, S., Fernández, Á.G., Inés Fernádez, A., Grágeda, M., 2015. Lithium in thermal energy storage: A state-of-the-art review. Renewable and Sustainable Energy Reviews 42, 1106-1112. doi:10.1016/j.rser.2014.10.096

Garrett, D.E., 2004. Part 1 - Lithium, Handbook of Lithium and Natural Calcium Chloride. Academic Press, Oxford, pp. 1-235.

Intaranont, N., Garcia-Araez, N., Hector, A.L., Milton, J.A., Owen, J.R., 2014. Selective lithium extraction from brines by chemical reaction with battery materials. Journal of Materials Chemistry A 2, 6374. doi:10.1039/c4ta01101e

Kesler, S.E., Gruber, P.W., Medina, P.A., Keoleian, G.A., Everson, M.P., Wallington, T.J., 2012. Global lithium resources: Relative importance of pegmatite, brine and other deposits. Ore Geology Reviews 48, 55-69. doi:10.1016/j.oregeorev.2012.05.006

Liu, X., Chen, X., Zhao, Z., Liang, X., 2014. Effect of Na+ on Li extraction from brine using LiFePO4/FePO4 electrodes. Hydrometallurgy 146, 24-28. doi:10.1016/j.hydromet.2014.03.010

Meshram, P., Pandey, B.D., Mankhand, T.R., 2014. Extraction of lithium from primary and secondary sources by pre-treatment, leaching and separation: A comprehensive review. Hydrometallurgy 150, 192-208. doi:10.1016/j.hydromet.2014.10.012

Moreno, L., 2013. Lithium Industry, a Strategic Energy Metal - Significant Increase in Demand Ahead.

Nishihama, S., Onishi, K., Yoshizuka, K., 2011. Selective Recovery Process of Lithium from Seawater Using Integrated Ion Exchange Methods. Solvent Extraction and Ion Exchange 29, 421-431. doi:10.1080/07366299.2011.573435

Preston, J.S., Whewell, R.J., 1977. Purification and acid-base properties of hydroxyoxime extractants for copper. Journal of Inorganic and Nuclear Chemistry 39, 1675-1678. doi:10.1016/0022-1902(77)80125-5

Szymanowski, J., 1993. Hydroxyoximes and copper hydrometallurgy. CRC Press, Boca Raton.

Talens Peiro, L., Villalba Mendez, G., Ayres, R.U., 2013. Lithium: Sources, Production, Uses, and Recovery Outlook. JOM 65, 986-996. doi:10.1007/s11837-013-0666-4

United States Geological Survey, 2015. Mineral Commodity Summaries 2015, Mineral Commodity Summaries. U.S. Geological Survey. 